\title{
Congenital multiple colonic atresias with intestinal malrotation: a case report
}

\author{
Daisuke Ishii, Hisayuki Miyagi, Masatoshi Hirasawa and Kazutoshi Miyamoto
}

\begin{abstract}
Background: Congenital intestinal atresia develops in 1 in 1500 to 20,000 births. Colonic atresia, which accounts for 1.8-15\% of intestinal atresia cases, is accompanied by other gastrointestinal atresias such as small intestinal atresia, gastroschisis, imperforate anus, and intestinal malformation in 47-80\%. Although a report shows that patients with multiple colonic atresias are $8.9 \%$ of those with colonic atresia.

Case presentation: A male infant did not have the first bowel movement within $36 \mathrm{~h}$ of birth and had abdominal distention/vomiting. Radiography showed significant dilation of the intestinal tract. A contrast enema examination at 3 days of age showed a microcolon and disruption in the descending colon. We performed an emergency decompressive loop enterostomy in the distended segment. At the age of 7 months, imaging from the stoma showed disruption of the contrast medium in the intestinal tract at the right lower abdomen, and the continuity of the intestinal tract was not clarified. Intestinal malrotation was found during the second surgery, and the enterostomy was located in the ileum proximal to Bauhin's valve. Continuity of the intestinal serosal surface was maintained. However, multiple membranous obstructions (three atresias and one stenosis) were observed in the distal segment of the bowel, which was penetrated by intraluminal advancement of a urethral catheter. Therefore, he was diagnosed with multiple colonic atresias. The intestinal tract was longitudinally incised, and membranectomy and mucosal/lateral suture were performed.
\end{abstract}

Conclusions: It is important for neonates with intestinal atresia to evaluate and prepare for distal patency of the colon before radical anastomosis. In addition, anomalies associated with colon atresia should also be assessed.

Keywords: Colonic atresia, Multiple, Intestinal malrotation, Microcolon

\section{Background}

Congenital intestinal atresia develops in 1 in 1500 to 20, 000 births $[1,2]$. Colonic atresia, which accounts for $1.8-15 \%$ of intestinal atresia cases $[3,4]$, is accompanied by other gastrointestinal atresias such as small intestinal atresia, gastroschisis, imperforate anus, and intestinal malformation in $47-80 \%$ [5]. Although a report shows that patients with multiple colonic atresias are $8.9 \%$ of those with colonic atresia [6], there have been three reports of multiple colonic atresias with malrotation according to our most extensive search. However all three reports were TypeIII atresias. We report a case of

\footnotetext{
* Correspondence: d-ishii@asahikawa-med.ac.jp

Department of Pediatric Surgery, Asahikawa Medical University, 2-1-1, Midorigaoka-higashi Asahikawashi, Hokkaido 078-8510, Japan
}

congenital multiple colonic atresias (TypeI) with intestinal malrotation, along with a literature review.

\section{Case presentation}

The course of pregnancy was normal. The infant was born at a gestational age of 38 weeks and 6 days by normal vaginal delivery, and birth weight was $2790 \mathrm{~g}$ at the previous hospital. The infant did not have the first bowel movement within $36 \mathrm{~h}$ of birth and had abdominal distention and vomiting. Plain abdominal radiography showed significant dilation of the intestinal tract and no gas in the pelvic cavity (Fig. 1), which did not respond to catheterization with a Nelaton's catheter or enema. A contrast enema examination at 3 days of age (Fig. 2) showed a microcolon and disruption in the descending
Springer Open

(c) The Author(s). 2020 Open Access This article is licensed under a Creative Commons Attribution 4.0 International License, which permits use, sharing, adaptation, distribution and reproduction in any medium or format, as long as you give appropriate credit to the original author(s) and the source, provide a link to the Creative Commons licence, and indicate if changes were made. The images or other third party material in this article are included in the article's Creative Commons licence, unless indicated otherwise in a credit line to the material. If material is not included in the article's Creative Commons licence and your intended use is not permitted by statutory regulation or exceeds the permitted use, you will need to obtain permission directly from the copyright holder. To view a copy of this licence, visit http://creativecommons.org/licenses/by/4.0/. 


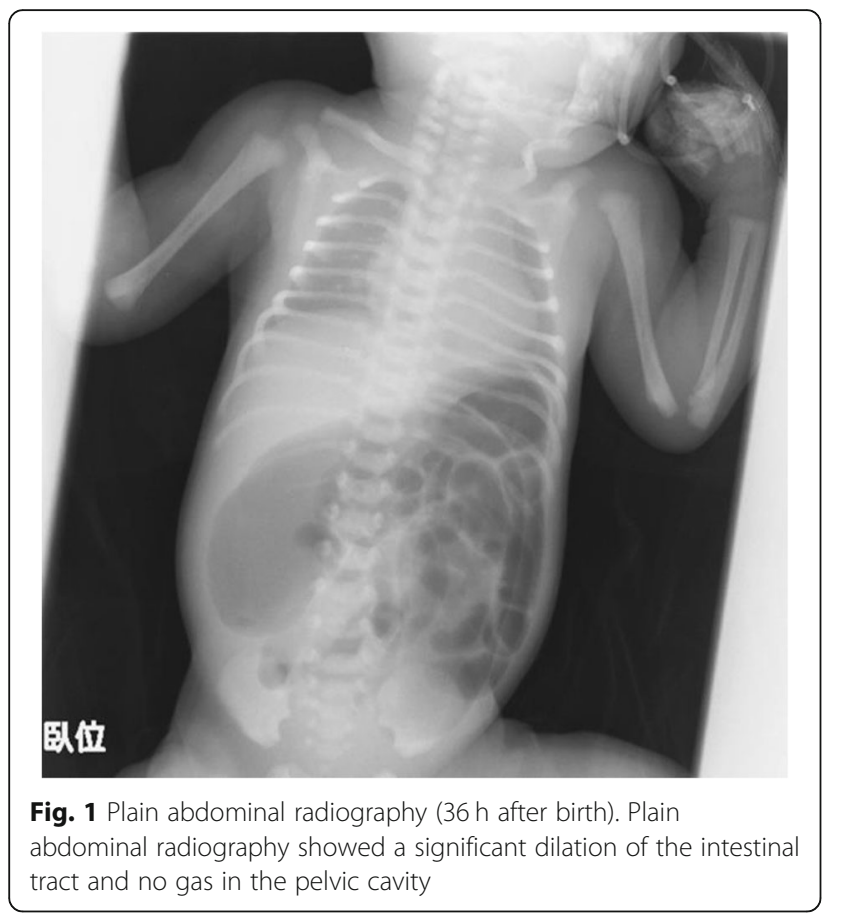

colon. Taking intestinal atresia, Hirschsprung's disease, and hypoplastic left hemicolon as a preoperative diagnosis into consideration, he was transferred to our hospital.

Because of his unsteady breathing condition, we performed emergency enterostomy at 3 days after birth. Laparotomy, with $3 \mathrm{~cm}$ transection in the upper right abdomen, observed serous ascites, but no adhesion was

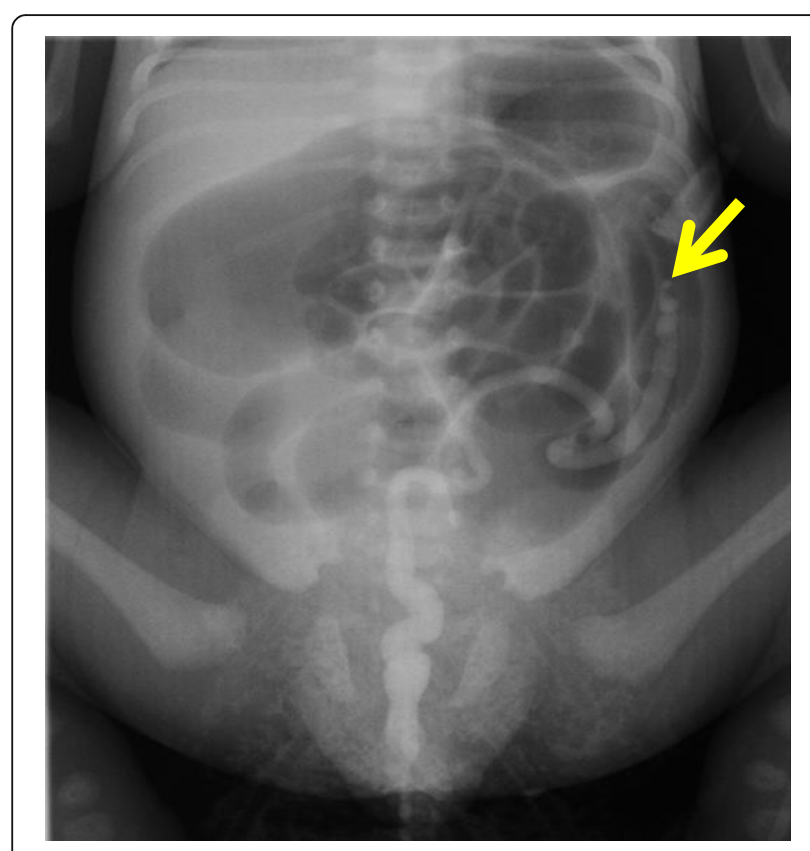

Fig. 2 Contrast enema examination ( 3 days of age). The arrow showed a microcolon and disruption in the descending colon observed. After puncturing the dilated intestinal tract and depressurizing, we performed only emergency enterostomy with double orifices for the dilated intestinal tract. During the operation, we wanted to confirm distal patency and associated anomalies and make a definitive diagnosis, but we could not do it due to prominent intestinal dilatation and his unsteady breathing condition.

A biopsy of the intestinal tract at the site of enterostomy showed ganglion cells in the Meissner's and Auerbach's plexus. And a biopsy of the rectal mucosa showed ganglion cells in the Meissner's plexus. Therefore, Hirschsprung's disease was ruled out. As associated anomalies, the infant had Ebstein's anomaly (mild) and mild pyelectasis on the left side (I-II). His family history was noncontributory.

He was admitted to our department to undergo radical operation at 7 months of age. The height was $65.1 \mathrm{~cm}$ and weight was $6.53 \mathrm{~kg}$. Preoperative contrast enema from the anus showed a microcolon and disruption of the contrast medium in the descending colon. Imaging from the stoma showed a disruption of the contrast medium in the intestinal tract at the right lower abdomen, and the continuity of the intestinal tract on both sides was not clear (Fig. 3).

Laparotomy, with transection in the lower abdomen, showed a complicated non-rotation type of intestinal malrotation, and the enterostomy was located in the ileum proximal to Bauhin's valve. We removed the ileostomy once to confirm distal patency. The continuity of the intestinal serosal surface was maintained, whereas in the lumen, there were 3 membranous atretic sites and 1 stenotic site; (1) a membrane-like atresia in the Bauhin's valve, (2) a membrane-like atresia in the $2-\mathrm{cm}$ anal side of Bauhin's valve, (3) a membrane-like atresia in the transverse colon, and (4) a stricture in the $2-\mathrm{cm}$ anal side of the atresia (Fig. 4). For the three membrane-like atresias (TypeI), the intestinal tract was longitudinally incised, and membranectomy and mucosal/lateral suture were performed. We only performed longitudinal incision/lateral suture for the constricted intestinal tract. Finally, the ileostomy was reconstructed at the same ileal site. The operative time was $2 \mathrm{~h} 59 \mathrm{~min}$, and blood loss was $55 \mathrm{~g}$. The postoperative course was favorable, and he was discharged on day 14 postoperatively.

Pathologically, the wall structure of the membrane-like atresias was maintained, and mucosal epithelial regenerative changes were observed (Fig. 5). Ganglion cells were present in the Meissner's and Auerbach's plexus. In the resected membranes of the atresias in the Bauhin's valve and ascending colon, the muscle layer structure was unclear in the entire specimens, and the muscle layer was occupied by hyperplastic connective tissue, mainly composed of collagen fibers, in which defect and developmental abnormalities of the muscle layer were suspected as the causes of atresia. 


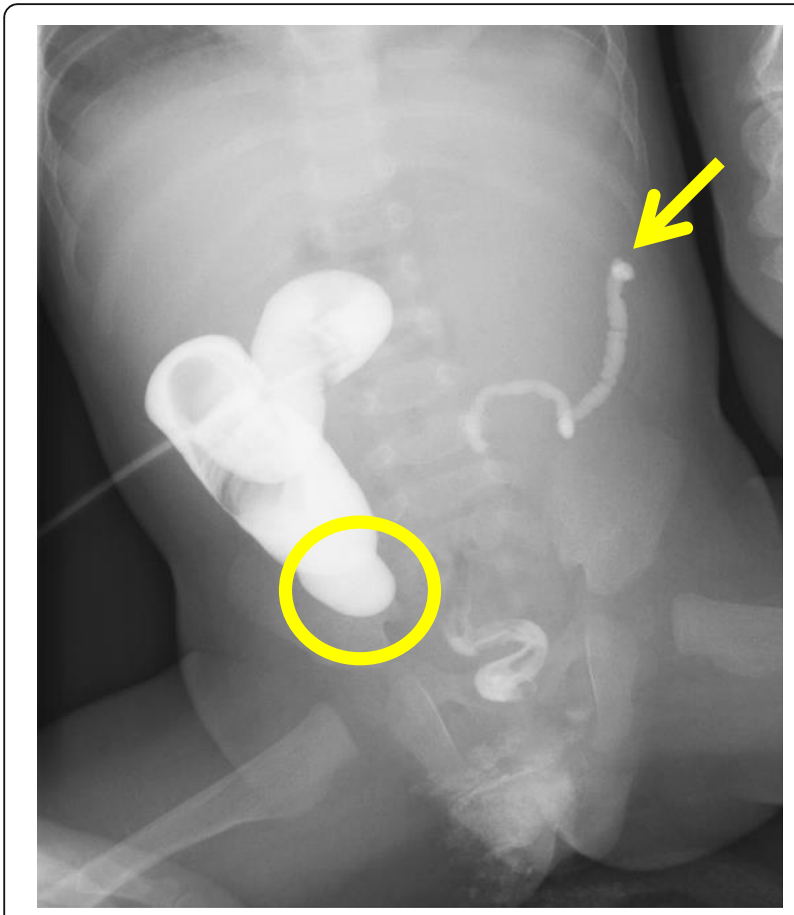

Fig. 3 Preoperative contrast enema examination (7 months of age). Imaging from the anus showed a microcolon and disruption of the contrast medium in the descending colon (arrow). Imaging from the stoma showed a disruption of the contrast medium inside the intestinal tract in the right lower abdomen (circle), and the continuity of the cecum and intestinal tract on both sides was not clear

At 9 months of age, he was admitted for the ileostomy closure. Simulated stool had been injected into the intestinal tract in the anal side of the stoma 7 days before surgery. A contrast enema examination confirmed the improvement in disuse atrophy of the intestinal tract and its passage. But at operation a stricture was observed in the region where the membrane-like atresia in the transverse colon was removed. We performed a balloon

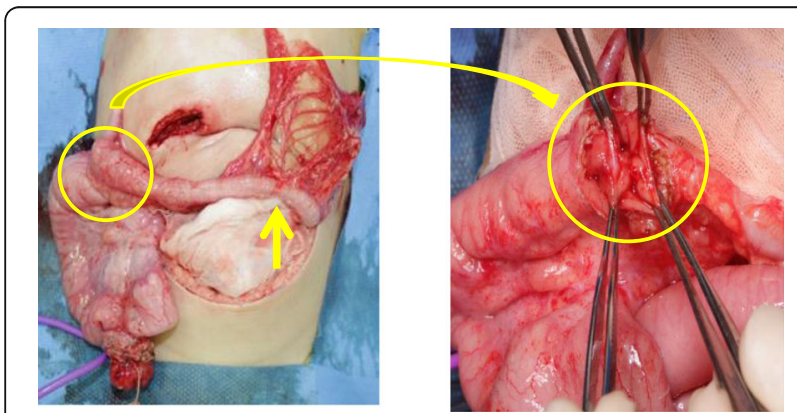

Fig. 4 Operative findings. The continuity of the intestinal serosal surface was maintained, while, as for the lumen, there were membranous atresias in the Bauhin's valve and anus, $2 \mathrm{~cm}$ from the Bauhin's valve (circle), and a membranous atresia in the transverse colon and stricture in the anus, $2 \mathrm{~cm}$ from the atresia (arrow)

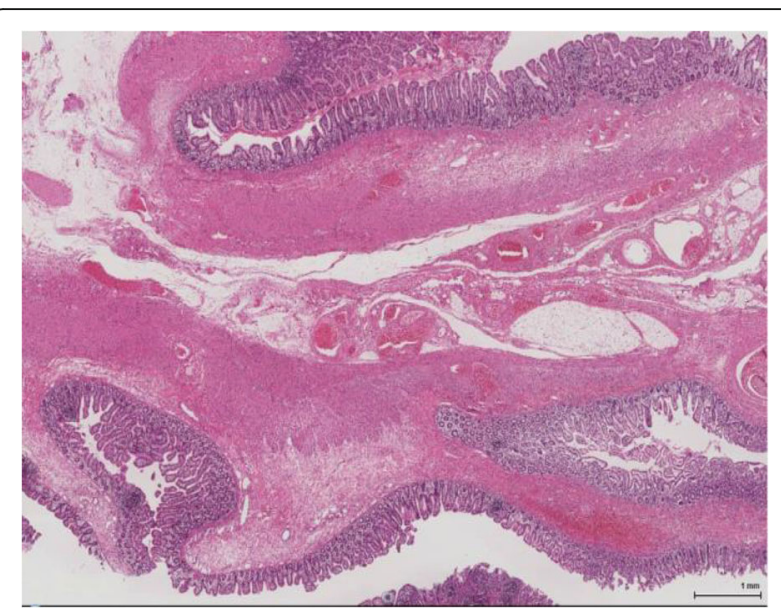

Fig. 5 Pathological diagnosis. The wall structure in membranous atresias was maintained, and mucosal epithelial regenerative changes were observed. In the resected membranes of the atresias in the Bauhin's valve and ascending colon, the muscle layer structure was unclear in the entire specimens, and the muscle layer was occupied with hyperplastic connective tissue

dilation and the ileostomy closure. The postoperative course was favorable, and the baby was discharged on day 11 after surgery. Currently, he has outpatient followup visits, and the control of defecation is favorable.

\section{Discussion}

Colonic atresia, a type of congenital intestinal atresia that develops in the colon, was first reported by Binninger et al. in 1873, and a lifesaving case was reported by Gaub et al. in 1922 [7]. Congenital intestinal atresia develops in 1 in 1500 to 20,000 births [1,2], and colonic atresia is shown to account for $1.8-15 \%$ of them $[3,4]$. We had 75 patients with congenital intestinal atresia between 1989 and 2017 in our department, of whom, five patients $(6.7 \%)$ had colonic atresia. Although a report shows that patients with multiple colonic atresias are $8.9 \%$ of those with colonic atresia [6], there have been three reports of multiple colonic atresias with malrotation according to our most extensive search (Table 1) [8, 9] (excluding patients with familial intestinal polyatresia (FIPA) syndrome stated below). All three reports were TypeIII atresias with our case being the first reported case of TypeI atresias.

The causes of congenital intestinal atresia are explained by the theory of developmental anomaly due to failure of recanalization by Tandler et al. [10] and the theory of vascular insufficiency by Louw et al. [11]. In the present case, atresia was categorized as type I in Louw's classification; there was no finding that suggests vascular insufficiency, including no abnormality in the mesentery; and the pathological diagnosis showed findings in which developmental anomaly was suspected, so 
Table 1 Reports of multiple colonic atresias with malrotation

\begin{tabular}{|c|c|c|c|c|c|c|c|c|}
\hline & Birth weight & Gastational age & Time of first surgery & Atresias & Type & First surgery & Anomalies & Ref \\
\hline 1 & $\mathrm{~nm}$ & 40 weeks & $52 \mathrm{~h}$ & $A, T, D$ & III & Ostomy & Malrotation & 8 \\
\hline 2 & $\mathrm{~nm}$ & 40 weeks & $48 \mathrm{~h}$ & $\mathrm{~T}, \mathrm{Sp}$ & III & Ostomy & Malrotation & 8 \\
\hline 3 & $\mathrm{~nm}$ & 34 weeks & $12 \mathrm{~h}$ & $\mathrm{~A}, \mathrm{H}, \mathrm{T}$ & III & Ostomy & Gastroschisis, malrotation & 9 \\
\hline 4 & $2790 \mathrm{~g}$ & 38 weeks & $72 \mathrm{~h}$ & $A, T$ & । & Ostomy & Ebstein's anomaly, pyelectasis, malrotation & Our case \\
\hline
\end{tabular}

$\mathrm{nm}$ not mentioned, $A$ ascending colon, $T$ transverse colon, Sp sigmoid colon, $D$ descending colon

failure of recanalization was considered to be the cause of the disease. But we cannot explain the cause of multiple atresias because of only failure of recanalization. As a cause of multiple atresias, vascular insufficiency due to gastroschisis and FIPA syndrome $[12,13]$ are common causes to be discriminated. The present case had no findings to suggest them. So, multiple atresias can be caused by various factors. Further case accumulation and analysis are required.

Combined malformation is shown to occur in $47-80 \%$ of patients with colonic atresia [5, 6], and atresia of the other gastrointestinal tracts, such as small intestinal atresia, gastroschisis, imperforate anus, intestinal malrotation, cardiac malformation, omphalocele, and Hirschsprung's disease, have been reported [6]. The most common of the combined malformation is gastroschisis. Intestinal malrotation is less common as the combined malformation [14, 15].

Since in colonic atresia, due to the presence of the Bauhin's valve, which is different from intestinal atresia in other regions, closed loop obstruction occurs, the onset of abdominal distention and vomiting is delayed, and symptoms commonly occur after $24 \mathrm{~h}$ of birth. Therefore, necrosis and perforation easily occur, and early diagnosis is necessary. A report showed that, in patients who underwent surgery over $72 \mathrm{~h}$ after birth, the mortality is significantly higher than those who had surgery within $72 \mathrm{~h}$ after birth, and the cause of death is perforation due to dilation of the occluded colon in the rostral portion [8]. For the atresia in the right colon, one-stage surgery, in which anastomosis is performed at the first surgery, and for the atresia in the left colon, multiplestage surgery, in which anastomosis is performed after colostomy, have been recommended [16]. However, onestage surgery is advantageous in that it requires fewer surgeries, but the risks of ileocecal resection, anastomotic leak, and sepsis are shown to be high [6]. Multiple-stage surgery allows safe decompression of an anastomotic site as well as a dilated intestinal tract, and this is advantageous in the conservation of the ileocecal valve. However, it is disadvantageous in that it requires more number of surgeries. Because our patient had a significant dilation of the intestinal tract at the first surgery, we could not confirm distal patency and make a definitive diagnosis and we judged that the risk of complication would be high in one-stage surgery, and performed emergency enterostomy. In a case of mild dilation of the intestinal tract, one-stage surgery can be performed. However, in a case of potential multiple atresias, as in our patient, and a case of colonic atresia, combined malformation is common, and we consider that by performing multiple-stage surgery, radical operation, after a preoperative sufficient examination of the intestinal tract, is safe.

\section{Conclusions}

It is important for neonates with intestinal atresia to evaluate and prepare for distal patency of the colon before radical anastomosis. In addition, anomalies associated with colon atresia should also be assessed. In a case of potential multiple atresias, we consider that by performing multiple-stage surgery, radical operation, after a preoperative sufficient examination of the intestinal tract, is safe.

\section{Abbreviations}

FIPA: Familial intestinal polyatresia

\section{Acknowledgements}

We thank Editage (www.editage.jp) for the English language editing.

\section{Authors' contributions}

These authors saw this case in the department of surgery, and equally contributed for preparation of this manuscript. DI, HM, MH, and KM performed the surgical procedure. DI contributed to the drafting of the manuscript and literature review. DI obtained consent from the patient. KM is the director of the department. DI, HM, and $\mathrm{MH}$ managed to preoperative and postoperative course. $\mathrm{HM}, \mathrm{MH}$, and $\mathrm{KM}$ instructed of the overall description of this manuscript. All the authors critically appraised the manuscript and contributed to make necessary changes in the article. All authors read and approved the final manuscript.

\section{Funding}

None.

Availability of data and materials Not applicable.

Ethics approval and consent to participate Not applicable.

\section{Consent for publication}

Written informed consent was obtained from the patient for publication of this case report and any accompanying images.

Competing interests

The authors have no competing interests to declare. 
Received: 23 November 2019 Accepted: 19 March 2020

Published online: 30 March 2020

\section{References}

1. Evans CH. Atresias of the gastrointestinal tract. Int Abstr Surg. 1951;92:1-8.

2. Webb $\mathrm{CH}$, Wangsteen $\mathrm{OH}$. Congenital intestinal atresia. Am J Dis Child. 1931;41:262-84.

3. Pohlson EC, Hatch El Jr, Glick PL, et al. Individualized management of colonic atresia. Am J Surg. 1988;155:690-2.

4. Dalla Vecchia LK, Grosfeld JL, West KW, et al. Intestinal atresia and stenosis: a 25-year experience with 277 cases. Arch Surg. 1998;133:490-7.

5. Wilson BJ, Nelson A, Harshbarger M. Congenital atresia of the colon. Surg Gynecol Obstet. 1954;99:34-41.

6. Takenouchi A, Yoshida H, Matsunaga T, et al. A case of congenital colonic atresia with ileal stenosis. J Jpn Soc Pediatr Surg. 2004;40:884-9.

7. Fuller JW, Scarano VR. Congenital atresia of the colon. South Med J. 1977;70: 987-90.

8. Etensel B, Temir G, Karkiner A, et al. Atresia of the colon. J Pediatr Surg. 2005;40:1258-68.

9. Barsoom MJ, Prabulos A, Rodis JF, et al. Vanishing gastroschisis and shortbowel syndrome. Obstet Gynecol. 2000;96:818-9.

10. Tandler I. Zur Entwicklungsgeschichte des Menschlichen Duodenum in Fruhen Embryonalstadien. Gegenbaurs Morphol Jahrb. 1902;29:187-215.

11. Louw JH, Barnard CN. Congenital intestinal atresia; observations on its origin. Lancet. 1955;269:1065-7.

12. Mishalany HG, Der Kaloustian VM. Familial multiple-level intestinal atresias: report of two siblings. J Pediatr. 1971;79:124-5.

13. Cole C, Freitas A, Clifton MS, et al. Hereditary multiple intestinal atresias: 2 new cases and review of the literature. J Pediatr Surg. 2010;45:21-5.

14. El-Asmar KM, Abdel-Latif M, Abdel-Hamid A, El-Kassaby, et al. Colonic atresia: association with other anomalies. J Neonat Surg. 2016;5:47.

15. Karnak I, Ciftci AO. Mehmet Emin Senocak, et al. Colonic atresia: surgical management and outcome. Pediatr Surg Int. 2001;17:631-5.

16. Benson CD, Lofti MW, Brough AJ. Congenital atresia and stenosis of the colon. J Pediatr Surg. 1968;3:253-7.

\section{Publisher's Note}

Springer Nature remains neutral with regard to jurisdictional claims in published maps and institutional affiliations.

\section{Submit your manuscript to a SpringerOpen ${ }^{\odot}$ journal and benefit from:}

- Convenient online submission

- Rigorous peer review

- Open access: articles freely available online

- High visibility within the field

- Retaining the copyright to your article

Submit your next manuscript at $\boldsymbol{\nabla}$ springeropen.com 